\title{
LEMBRANÇAS QUE AMARGAM: A INFÂNCIA COMO LUGAR DE DESCONFORTO EM ME NINA, DE GUSTAVO BERNARDO
}

\author{
Ana Lidia da Silva Afonso \\ Doutoranda em Letras Vernáculas pela Universidade Federal do Rio de Janeiro (UFRJ) \\ anbraga81@gmail.com
}

\begin{abstract}
RESUMO
Narrativa com muitos vazios a serem suplementados, esperando "que o leitor descubra suas próprias projeções", conforme entendimento de Wolfgang Iser, o romance Me nina nos oferece exercício constante de estímulo à imaginação. De tantas questões que surgem ao longo do relato são as que envolvem o(s) narrador(es) que mais nos chamam a atenção. A sobreposição de vozes narrativas abre ao leitor a possibilidade de enxergar os fatos através de várias perspectivas que, longe de constituíremse como zonas de conforto, fazem do texto uma ficção cética. Os narradores assumem papel fundamental para dar conta de que a trajetória da personagem Timo é marcada pela impossibilidade. Texto de fruição, conforme ideias de Roland Barthes, a narrativa coloca-nos em estado de perda e desconforto, firmandose como leitura desejante e em constante devir.
\end{abstract}

Palavras-chave: infância, desconforto, narrador, ficção cética.

\section{RESUMEN}

Narrativa con muchos vacíos a ser suplidos, esperando "que el lector descubra sus propias proyecciones", según entendimiento de Wolfgang Iser, la novela Me nina nos ofrece ejercicio constante de estímulo a la imaginación. De tantas cuestiones que surgen a lo largo del relato son las que envuelven el (los) narrador(es) que más nos llaman la atención. La superposición de voces narrativas abre al lector la posibilidad de ver los hechos a través de varias perspectivas que, lejos de constituirse como zonas de confort, hacen del texto una ficción escéptica. Los narradores asumen un papel fundamental para dar cuenta de que la trayectoria del personaje Timo está marcada por la imposibilidad. Texto de fruición, según las ideas de Roland Barthes, la narrativa nos ponen en estado de pérdida e incomodidad, firmándose como lectura deseante y en constante devenir.

Palabras-clave: infancia, incomodidad, narrador, ficción escéptica. 


\section{Palavras iniciais}

A literatura brasileira contemporânea compõe-se por textos que seguem tendências estéticas distintas. Algumas produções surgem com o propósito de atender a demanda do mercado editorial. Nesse caso, os autores optam pelas fórmulas prontas. Mas há os escritores que trilham o caminho da experimentação, ocupando "espaços próprios", como afirma Dau Bastos (2009).

Vencendo os desafios impostos por uma fase que se inicia de forma conturbada, resultante de um contexto de censura e medo, parte dos autores volta-se para escritas que problematizam o período, elegendo temáticas que tratam das questões sociais, políticas e econômicas.

Os textos literários tendem a refletir a realidade externa, abandonando temas tradicionalmente utilizados pela literatura moderna como a solidão do homem, as crises existenciais, a angústia. Essas mudanças de paradigma podem ser percebidas com mais força nas produções do período pós-ditadura, momento propício para sair do atravancamento imposto pelo cerceamento da liberdade de expressão.

As transformações ocorrem não só no que se refere à temática, mas no que diz respeito à forma. Muitos autores provam outras possibilidades estéticas por meio da alegoria, da fragmentação, do documentarismo histórico, etc.

Foi esse o percurso que Gustavo Bernardo trilhou ao escrever Me nina. Opta pela experimentação, produzindo um texto de memórias que se estrutura pela via da fragmentação e da mescla de gêneros.

Publicado em 1989, o romance é reconhecido por Bernardo como texto que parte de dados biográficos da história familiar dele. Segundo o autor, sua mãe sempre quis ter 
uma menina, mas as tentativas foram infrutíferas, nascendo quatro meninos. Então, escrever o enredo foi um desafio, conforme afirma o próprio escritor. Para ele que "queria criar uma história com essa menina... O desafio era ser e, ao mesmo tempo buscar a delicadeza feminina" (BERNARDO, 2012a, p. 197).

Ao escolher a temática da infância, que nesse romance é retratada como lugar de desalento, Gustavo Bernardo distancia-se das propostas temáticas comuns naquele momento histórico que tinha como principal caminho refletir as questões sociais. Mas não abre mão de elaborar um texto experimentalista com a propriedade de um escritor que se preocupa em não cair no pedantismo e no didatismo.

Produzindo um texto que tem a base em episódios de sua biografia, tais referências são utilizadas como pretexto para a construção de uma narrativa que demonstra uma intensa preocupação com a linguagem.

O romance Me nina suscita algumas reflexões que nos instigam, desafiam, inquietam. Texto de fruição, conforme ideias de Roland Barthes (2004), a narrativa coloca-nos em estado de perda e desconforto, constituindo-se como leitura desejante.

Denso, com episódios curtos em um livro com 91 páginas, o enredo tem tanto a revelar sobre a complexa existência da personagem Timo e das vivências em seu núcleo familiar quanto qualquer outro romance mais extenso. A escolha pela escrita de um texto que aparenta dizer o mínimo não nos furta a experiência do constante devir. Afinal é o próprio narrador que afirma: "escrever não iguala com revelar" (BERNARDO, 2013, p. 14).

Texto que pode ser categorizado, entre outras possibilidades, como narrativa fragmentária, Me nina constrói-se através da técnica de cortes e ausência de linearidade. Sua estrutura utiliza uma linguagem que se compõe, quase sempre, com o uso de frases 
nominais e frases curtas, que dão ao mesmo tempo a sensação de incompletude e movimento aos fatos narrados.

Esse é um dos motivos que fazem do texto de Gustavo Bernardo uma leitura desconfortante e que coloca o leitor em estado de perda, conforme afirma Roland Barthes (2004). A sensação de que falta algo a ser dito, gera no leitor o desejo por buscar possíveis significados para além do que está escrito.

\section{As memórias do bosque Solidão}

O livro conta a história de Timo, relatos de sua infância, que são rememorados na vida adulta. Lembranças dos episódios que começam a ser contados na tarde de São João, dia do aniversário da personagem. Na ocasião, parentes e vizinhos estão reunidos no quintal da casa da tia dele ansiosos pela notícia e o início das comemorações.

Nas primeiras linhas do prólogo, Timo assume o papel de narrador-personagem, apresentando por meio de uma linguagem poética os fatos que precedem e, de certa forma, elucidam os acontecimentos que vão ser desenrolados na trama. No primeiro parágrafo o leitor é convidado à embarcar no universo infantil pela via de uma tradicional cantiga de ninar que é responsável por resumir e dar o tom de toda a narrativa - "Se esta rua fosse minha eu mandava ladrilhar com pedrinhas de brilhantes para o meu amor passar" (BERNARDO, 2013, p. 9).

A escolha por esse trecho da cantiga de ninar, canção familiar para todos os leitores que foram embalados, principalmente, no convívio materno quando crianças, levam a crer que as lembranças que serão apresentadas seguem o estilo romântico de recorrência 
ao tema da infância de maneira nostálgica e com o desejo de evadir-se para um lugar feliz.

Contudo, a conjunção subordinativa condicional "se" seguida do verbo "fosse" "ser" no pretérito imperfeito do modo subjuntivo, utilizado para expressar desejos, probabilidades - são as principais pistas que advertem o leitor sobre um percurso narrativo que não se pretende idealizado e que está longe de chegar ao habitual desfecho dos contos de fadas: e foram felizes para sempre.

A impossibilidade de ladrilhar a rua com pedrinhas de brilhantes capazes de criar uma paisagem bela, harmônica, perfeita, ideal, reflete metonimicamente a incapacidade da personagem de escrever sua história conforme seu gosto. A vida/rua segue seu curso, por vezes por caminhos tortuosos. Percursos que impuseram a Timo a tão esperada notícia, que se desdobra em três e são servidas aos parentes e vizinhos antes de qualquer outro quitute da festa: o nascimento de Taman, irmão de Timo; o não nascimento de Talia, irmã gêmea de Taman; a morte da mãe.

Antes mesmo das notícias serem veiculadas, o leitor é estimulado a fazer um exercício imaginativo, conforme entende Wolfgang Iser (1979), pois o vazio da interrupção da canção sugere a possibilidade de atualizar o texto. Nesse caso, o "vazio suplementado, aumenta a atividade imaginativa do leitor" (1979, p. 118).

A pausa indicia que a vida/rua trilhada por Timo reserva à personagem uma existência solitária e carente de afetos, pois a cantiga de ninar continua para além do narrado - "nessa rua tem um bosque, que se chama solidão / dentro dele mora um anjo que roubou meu coração" (VILLA-LOBOS, 1925).

A partir da notícia da morte da mãe e da irmã, a vida de Timo parece entrar em estado de suspensão, marcado pela noite dos trágicos acontecimentos. Noite que para a 
personagem insiste em não findar: “Mamãe morta há dias. A cor-de-rosa esmaeceu há dias. No entanto, não há dia: à noite sucede apenas a noite" (BERNARDO, 2013, p. 21).

Ao viver uma rotina que ocorre "notidianamente", sentindo falta da figura materna que jamais poderá ser substituída pela paterna, pois seu pai opta por enclausurar-se no silêncio e dor, Timo segue o curso de sua vida, acreditando que "amanhã há de ser outra noite" (BERNARDO, 2013, p. 19).

Anos depois, Timo agora é adulto e a noite de São João continua sendo o tempo propício para rememorar seu aniversário de sete anos. Momento de recuperar memórias como um trabalho que se faz sobre o tempo vivido, conforme entende Ecléa Bosi (2003), e tão vivo das lembranças de uma época em que, embora passada, "Nada mofara. / Tudo parece recente" (BERNARDO, 2013, p. 69). Lembrança do pai chegando do hospital, atravessando o portão, tão triste e frágil com a notícia que tem vontade de oferecer-lhe leite quente e acalentá-lo em seus braços.

Recordações de Taman chegando a casa aos berros, sentido a falta do leite materno. Reminiscências do estado de choque que a notícia lhe causou - "Timo não chora, nem com o tapa" (BERNARDO, 2013, p. 14) que a tia lhe dá por questionar o fato de ter que comer uma mãe-benta.

Memórias das tias, professoras aposentadas, que se desdobram em cuidados com os sobrinhos na tentativa de suprir um pouco a carência de cuidados e afetos que o pai dos meninos não pode dar. Fome de carinho que elas procuram compensar com os prazeres da culinária. Exercício de substituição fácil de aprender:

Aprender, o prazer é rápido e nos protege de nós. Aprender, o prazer uma boca cheia. Aprender: (a mulher uma mesa farta). Aprender que a dor não dói porque a fome se aborta na raiz subterrânea antes que nos dê à luz: com purê de batatas, com 
biscoitos maisena, com doce de nozes ou com brioche de queijo (BERNARDO, 2013, p. 19).

Essas são apenas algumas das muitas experiências que Timo e Taman terão que adquirir ao longo da vida: aprender a conviver com a perda, a superar a dor e os traumas, a fazer a travessia tão dura da infância para a vida adulta.

No caso de Timo, há outra lição a aprender: a de conviver com a ideia de que jamais poderá ocupar o lugar da tão desejada menina que a mãe tanto quis ter. Garota que não precisa ser forte, apenas dengosa para ter o colo do pai. Entender que é preciso superar a "vírgula antes do querer ser" (BERNARDO, 2013, p. 40), para alcançar a fase em que não necessite dizer Me nina.

Entretanto o tempo, habitualmente dinâmico, parece não contribuir para que as lembranças dos episódios tristes os deixem. E todos ficam ali estáticos, cada vez mais fechados no mundinho intramuros, onde o portão recebe mais um cadeado que passa a sensação de proteção diante das notícias de ladrões. Ladrões que, não sendo os que constam na Bíblia Sagrada (1969), versículo bíblico de João 10:10, possuem o mesmo sentido devastador de matar, roubar e destruir vidas que parecem não ter forças para suportar mais perdas.

Das memórias infelizes de Timo, uma parece causar maior desconforto: a presença de Taman, irmão que precisa amar apesar do ressentimento sentido por entender que ele ocupa um lugar que furtou de Talia e da mãe. Amargura que não era evidente na infância - idade que apesar dos pesares ainda guardava um pouco de inocência.

Lembranças dos anos que, embora sofridos, podiam ser vividos por ambos. Época que conseguiam darem-se as mãos e olharem na mesma direção. Cena de uma convivência perfeita aos olhos dos que observam o registro fotográfico, mas não podem 
ler os pensamentos dos meninos. Imagem capturada de uma ocasião "confortavelmente contida no frio de uma noite larga de junho muitos anos antes de depois de amanhã, quando eles tiverem tido seus filhos" (BERNARDO, 2013, p. 26).

Os meninos se transformam em homens e tentam deixar para trás os tempos de criança, mas parece impossível apartarem-se das recordações daquela noite que cresceu marcada por dois sentimentos antitéticos: a celebração da vida e o luto. Recordações que Timo e Taman hão de carregar "até que a memória os separe de si mesmos" (BERNARDO, 2013, p. 13).

Consciente de que a vida não é mais uma ciência exata, "quando dois mais dois não são mais quatro" (BERNARDO, 2013, p. 83), mesmo assim Timo tenta refazer o solitário percurso da rua/vida, revisitando a república argentina, escola onde estudou, na tentativa de exorcizar os fantasmas. Esse é um dos poucos momentos em que a claridade assume o lugar da noite - "Hoje não chove, o Sol a pino" (BERNARDO, 2013, p. 84). E o vocábulo notidianamente, que usualmente marca o período das trevas vivido pela personagem, agora dá lugar a outro termo: cotidianamente.

Embora o presente traga lembranças que amargam, e Timo ainda não consiga se livrar da noite, ele pode entrever uma luz no fim do túnel: percebe que está se aproximando da morte. Sente-se mais jovem e mais leve. E agora parece não ter mais medo da noite, nem de atravessar a avenida - "Sinto o escuro próximo com um prazer que não havia antes, nem mesmo dentro do beijo. Perdi o pavor de morrer feio, o que não deixa de ser um bom prêmio de consolação" (BERNARDO, 2013, p. 90).

\section{Pega essa criança, boi, boi, boi}


O tema da infância é muitas vezes apresentado na literatura de maneira simbólica ou alegórica, resultante de um olhar romântico que tende a representar essa fase, entre outras possibilidades como época da inocência, que sinalize para o novo ou ressalte a esperança no futuro.

No caso de Me nina, acreditamos que nenhum desses caminhos se sustente como vieses de leitura. Concernente à inocência, o narrador em 3a pessoa deixa bem claro que as notícias recebidas por Timo têm o poder de amadurecer qualquer pessoa.

A possibilidade de vislumbrar o novo fica atravancada nas memórias amargas de uma noite que parece não ter fim. E sobre a crença num futuro, "a esperança inverte porque amanhã há de ser outra noite" (BERNARDO, 2013, p. 90).

Ao revisitar as memórias da infância de Timo, escutando as vozes que surgem na narrativa, o leitor não vai ter o mesmo deleite produzido pelas suaves melodias das cantigas de ninar.

O romance constitui-se como desafio constante não só porque impõe que o ledor exercite para dar conta de preencher os sentidos deixados nos vazios da narrativa fragmentada, mas também pela tarefa de tentar ouvir a língua fora do poder, pois o autor opta por usar uma linguagem que se concebe como trapaça salutar, tal como entende Roland Barthes (2000).

Um dos recursos utilizados nessa trapaça e que potencializa o exercício imaginativo é a eleição de vários focos narrativos. Escolha que provoca algumas questões sobre o papel do(s) narrador(es) em Me nina: a dificuldade de estabelecer uma posição para o narrador estaria associada à ideia defendida por Adorno de que hoje não se pode mais narrar, "embora a forma do romance exija um narrador" (2003)? As mudanças de foco narrativo estariam ligadas ao que Silviano Santiago (2002) afirma ser a noção de 
autenticidade ou não que a voz do narrador imprime no texto de acordo com a troca de perspectiva? Ou a escolha de um narrador em 3a pessoa estaria aliada a outra visão de Santiago: a de que o narrador pós-moderno tenta extrair-se história, narrando a ação enquanto espetáculo no qual ele assiste da plateia?

Essas são algumas das questões inquietantes que surgem com as mudanças de foco narrativo, com a mescla de vozes, que ora surge de um narrador personagem, outra de um narrador em 3a pessoa, e que se desdobra na voz feminina de Talia. Vozes narrativas que em alguns momentos se misturam e esfacelam as fronteiras a ponto de não sabermos ao certo qual é a ótica de quem está contando a história.

Ao discorrer sobre os sujeitos ficcionais, Luís Brandão e Silvana Oliveira (2001) afirmam que há em alguns textos um profundo imbricamento de vozes, pois as falas das personagens são criadas pelo narrador, que assume o papel de sujeito da enunciação-agente que cria algum enunciado. O sujeito do enunciado pratica a ação narrada pelo sujeito da enunciação.

Esse imbricamento de vozes também pode ser notado no romance Me nina. Recorrer à sobreposição de vozes, principalmente quando Timo silencia para deixar o narrador em 3a pessoa falar, num primeiro momento pode ser entendido como uma necessidade da personagem de contar a sua história como um observador, tentando marcar seu distanciamento em relação aos fatos.

Outra possibilidade seria a que se explicita na voz da própria personagem, que diz ter o hábito de esconder-se atrás da própria história. Mas, nesse caso, pode-se perceber que, ao optar por mascarar-se,Timo revela mais que esconde, evidenciando o sentido dado por Biagio D’Angelo, no que diz respeito ao uso da máscara. Ela é "testemunha especial da falência da história, isto é, testemunha de uma impossibilidade a dizer e a 
narrar que se consolida no espaço do discurso literário. Esconde, mas revela ao mesmo tempo" (2009, p. 246).

É nesse jogo de esconder e revelar que os leitores ficam sabendo que Timo pode nunca ter sido embalado por sua mãe com cantigas de ninar: "Timo é meu bastante traidor: tem de me fazer escorregar o alívio que agora sente na certeza de ao menos não ter sido o pai a deixá-lo em paz, se mamãe nunca, ouviu bem, nunca: / : Ihe boi-boi" (BERNARDO, 2013, p. 14).

Nesse trecho da narrativa fica bem evidente a mistura das vozes. 0 narrador em $3 \underline{a}$ pessoa incorre num lapso que acaba revelando que há um esforço mal sucedido na tentativa de não deixar a máscara cair. Então, o narrador trai-se e joga no texto uma centelha que talvez seja a chave da caixa preta da vida de Timo: a ausência do carinho materno doía-lhe antes mesmo da morte dela.

Isso explica o incômodo da personagem com a vontade da mãe de querer ter uma menina. E talvez explique porque Talia ganha voz nas páginas finais da narrativa, fruto da insistência de Timo em não se desvencilhar das lembranças e, quem sabe, da necessidade de encenar a existência da irmã na esperança de, escondendo-se atrás dela, encontrar refrigério para sua alma e se livrar do drama e das mágoas, pois, como afirma o narrador,

Portanto Talia definiu-se quase quase para sempre e cumpriu seu lugar de primeira máscara dos fantasmas femininos: uma máscara sem boca, sem cabelos e sem calor, uma máscara muito suave, um pouco brejeira e dengosa como a criança de dois anos filha única e bem-amada, uma máscara sensual como se tivesse quinze anos e os olhos brilhassem (BERNARDO, 2013, p. 84). 
Um dos indícios das memórias desconfortáveis da personagem, a máscara do fantasma feminino de Talia, gera mais uma questão: negar-se a possibilidade de Ser estaria ligada ao fato de Timo ter dificuldades de aceitar a ideia de que precisa abandonar o espectro que o persegue?

Tanto narrando em 1a pessoa como recorrendo ao narrador em 3a pessoa, a história contada suscita muitas dúvidas. O fato do narrador em $3^{3}$ pessoa sentir-se traído por Timo, deixando que o personagem interfira na sua fala, é um exemplo de que os discursos produzidos por eles devem ser lidos com desconfiança.

O imbricamento de vozes é uma das evidências que possibilitam afirmar que Me nina é um texto ficcional cético. No entendimento de Gustavo Bernardo (2012b) o ceticismo ficcional tem a função de "nos perspectivizar", colocando-nos na perspectiva do narrador ou do personagem.

No romance, é possível notar claramente como os diferentes pontos de vistas do narrador impõem-nos uma mudança de perspectiva. Por um lado, temos um narrador em 3a pessoa que tenta, sem sucesso, contar a história com certo distanciamento. Por outro, temos o narrador em 1a pessoa, voz que poderia ser considerada autorizada para falar de si mesmo, mas que é suspeita, pois ao assumir o papel de sujeito da enunciação, Timo, constrói um discurso em que sendo ele o "eu", simula outro "eu" que assume a função de sujeito do enunciado.

Pensando sob este ponto de vista, na possibilidade do narrador em primeira pessoa simular uma imagem de si mesmo, surge mais uma inquietação: teria sido a vida da personagem uma estrada de amarguras para todo o sempre, ou Timo se constrói e/ou se enxerga como alguém que é vítima das circunstâncias? 
É Gustavo Bernardo, ao refletir sobre a definição dada por Vilém Flusser acerca do espelho, quem nos ajuda a pensar um pouco acerca da imagem que Timo cria ao assumir a função de sujeito do enunciado. Segundo Bernardo, na visão do filósofo Flusser "o espelho como um ser que nega" (BERNARDO, 2012b, p. 4), pois seu reflexo impede quem observa de atravessar para além da imagem invertida.

Quando o espelho nos reflete, ele nos nega a possibilidade de nos vermos com mais profundidade. É diante desse espelho que, num primeiro momento, temos a sensação de que Timo constrói sua imagem, atravancado num Ser impedido pelo limite do reflexo. Conforme dito anteriormente, é possível notar que ele tem dificuldades de ultrapassar a fronteira imposta pela vírgula.

Além disso, tia Teresa põe em questão a nacionalidade dele, dizendo que não é brasileiro. E ele mesmo "sente, então, o difuso orgulho de nem ser alguma coisa" (BERNARDO, 2013, p. 16).

Limitar-se e aceitar a visão invertida do espelho é uma escolha. Há a possibilidade de um exercício mais atento, de se olhar no espelho de verdade, mais detidamente, por vários minutos, conforme propõe Gustavo Bernardo (2012b). Contudo os resultados podem não ser tão confortáveis, pois pode surgir a imagem de um monstro.

Timo não demonstra ou finge não ter consciência da fragilidade dessa imagem, fruto do reflexo.Talvez porque the seja melhor manter-se exatamente na posição de um Ser que se nega o direito de saber quem é de fato, por conveniência ou medo. Mas o narrador em 3a pessoa tem a exata dimensão da vulnerabilidade do "vidro multifacetado":

Onde o espelho onde o outro onde o espelho do outro. 
Não se pode fechar os olhos e dormir neste berço formado pelas velas, sombras das velas e pelos reflexos na pele dos braços. A mínima, mas a mínima fosforescência da íris no vidro multifacetado da cristaleira da sala, note bem, quebra! (BERNARDO, 2013, p. 28).

Tanto quando narra em 1모 pessoa, simulando outro "eu", ou quando apresenta os fatos em 3a pessoa, nota-se que as posições dos narradores não são confortáveis. As memórias da infância de Timo são marcadas por uma profunda melancolia e muita amargura.

Há na narrativa um momento singular em que é possível entrever que Timo parece estar em paz, quando encontra Maria de Cristo, seu primeiro e único amor. Pessoa a quem ele dedicaria seu tempo mandando ladrilhar a rua com pedrinhas de brilhante: "apenas para o meu amor passar" (BERNARDO, 2013, p. 10).

Essas memórias, Timo dedica com especial atenção dois capítulos do romance, dentro do beijo e a chuva. Episódios que mesclam a linguagem poética e erótica.

Em dentro do beijo, os relatos dos afetos se iniciam num tom quase pueril como as belas histórias do primeiro amor. Timo sente-se inseguro diante da amada, com medo do mundo. Atraído por ela que "chegou na festa descalça, com pés morenos e pequenos. Os cabelos encaracolados, escuros. / Rosto de criança, pernas de mulher, assim feito isso: feitiço" (BERNARDO, 2013, p. 47).

Os sentimentos que nutre por Maria de Cristo são comparados com o que há de mais sublime, o próprio nome da amada indicia isso. Afetos que fundem os dois sentidos distintos que o termo desejo agrega em sua etimologia, conforme explica Marilena Chauí (2006), a palavra "considerare", escolha pelo exame dos sentimentos com cuidado, 
considerando a influência dos astros, e "desiderium", a decisão de tomar o destino nas próprias mãos.

Timo se vê nesse dilema: entregar-se as suas vontades na busca pela completude, ou conter-se e tentar conduzir com mais cuidado os seus desejos. Mas uma coisa é certa, Maria de Cristo preenche os vazios da sua vida e tem o poder de fazê-lo enxergar o dia:

Eu te amo.

Quer dizer, eu não te amo, embora você já mais importante que tanto a completar o puzzle: o cheiro, a luz, o mosaico preenchido.

O mosaico preenchido que traz de volta o Sol, embora o Sol me envergonhe, embora eu já sinta vergonha de mim e de você juntos. Te quero tanto quanto não te quero, Cristo: que vergonha (BERNARDO, 2013, p. 48).

É na chuva, fenômeno que pode ser considerado simbolicamente como influências celestes recebidas pela terra, conforme Chevalier e Gheerbrant (1999), que há o encontro dos corpos molhados pelo pé d'água trazido pelo temporal.

Nos relatos, o desejo erótico que os envolve no momento do encontro está no plano do sagrado, conforme Bataille (2013). O sentimento que Timo e Maria nutrem um pelo outro se confunde com a busca do amor por Deus. É assim que Timo narra a união dos corpos ao procurarem a unidade: "Semi-silenciosamente, dá-se a cerimônia. Sagrada. O gesto. Sagrada" (BERNARDO, 2013, p. 52).

Mas o momento apaziguador se esvai, "timoneiros de brevíssima calmaria" (BERNARDO, 2013, p. 56), logo a vida volta a seu curso, e as lembranças que poderiam ser o caminho para atar os fios/as pontas do tempo se esgarçam, marcando, mais uma vez, a incapacidade de Timo de dar rumo à vida que tem consciência que não é dele - "Só que: a 
vida não é minha e eu me escondo ratinho atrás da história: aliás, como de praxe" (BERNARDO, 2013, p. 90-91).

Esconder-se ratinho atrás da história como sempre. Essas são as palavras finais de Timo para encerrar suas memórias. Afirmações que já haviam aparecido anteriormente ao longo da narrativa, mas que parece ganhar maior peso no momento que a narrativa termina. Termina? Evidente que não. Mais uma vez somos convidados a tentar preencher os vazios deixados no texto.

O narrador em 1ạ pessoa faz questão de se qualificar usando o diminutivo ratinho, dando-nos a sensação de pequenez e impotência diante dos fatos. Mas sabemos que o rato é um roedor, em alguns contextos pode ser considerado praga capaz de destruir produtos armazenados em estabelecimentos comerciais ou residenciais e pode até passar doenças.

Nesse sentido, proteger-se ratinho atrás da narrativa pode revelar o caráter corrosivo que a personagem tem de arruinar a própria história, corroborando com a ideia de que as perspectivas lançadas tanto por Timo quanto pelo narrador em 3 a pessoa deixam muito mais dúvidas que certezas.

\section{Considerações sobre uma escrita em devir}

Para além de pensar na posição do narrador no romance contemporâneo como o lugar da impossibilidade de narrar, conforme aponta Adorno (2003), entendemos que o caminho da experimentação trilhado por Gustavo Bernardo, sobretudo elegendo os vários pontos de vista, contribui para inserir seu romance no rol dos "bons livros" que 
têm algo especial para dizer, livre do impedimento imposto "pelo mundo da estandardização e pela mesmice" (ADORNO, 2003, p. 56).

Longe da preocupação em criar discursos que passem a noção de autenticidade ou não, apontadas por Silviano Santiago (2002), ao entrarem no jogo de esconder e revelar, os narradores deixam os leitores com mais dúvidas que certezas.

Também não é possível afirmar que Timo opte por ficar em silêncio, dando voz a um narrador em 3a pessoa, para assistir ao espetáculo da plateia, como entende Santiago, porque mesmo saindo de cena, ele continua atuando nos bastidores: seja através das máscaras ou corroendo a história como um ratinho.

Nesse sentido, os narradores assumem papel fundamental para dar conta aos leitores que as memórias da infância de Timo não são nada confortáveis e que as lembranças amargam. Desventuras que nos revelam uma trajetória marcada pela impossibilidade.

Narrativa com muitos vazios a serem suplementados, conforme Iser, esperando "que o leitor descubra suas próprias projeções" (ISER, 1979, p. 120). O texto nos oferece um exercício constante de estímulo à imaginação.

Mas são as ideias defendidas por Maurice Blanchot (2013), ao discorrer sobre os rumos que a literatura vem tomando e acerca da irrelevância da categorização do texto literário dentro de um gênero específico, que melhor sintetizam meu entendimento sobre essa obra - "Só importa o livro, tal como é, longe dos gêneros, fora das rubricas, prosa, poesia, romance, testemunho, sob as quais ele se recusa a abrigar-se e às quais nega o poder de lhe atribuir um lugar e de determinar sua forma" (BLANCHOT, 2013, p. 293). É assim que vemos a proposta literária de Gustavo Bernardo nesse romance. Livro em constante devir, Me nina não pertence a um único gênero, é somente literatura. 


\section{Referências}

ADORNO, Theodor W. Notas de literatura I. Tradução de Jorge M. B. de Almeida. São Paulo: Ed. 34, 2003.

BARTHES, Roland. Aula. 8 ed. São Paulo: Cultrix, 2000. O prazer do texto. São Paulo: Perspectiva, 2004.

BASTOS, Dau. Viva a vanguarda: literatura brasileira contemporânea à luz da ruptura. Revista Fórum de Literatura Brasileira. Rio de Janeiro: Baluarte, 2009, p. 34-51.

BATTAILLE, Georges. O erotismo. Tradução de Fernando Scheibe. Belo Horizonte: Autêntica, 2013.

BERNARDO, Gustavo. Me nina. 2 ed. São Paulo: Annablume, 2013. O risco da experimentação é resvalar para o pedantismo. Revista Fórum de Literatura Brasileira. 8 ed. Rio de Janeiro: Baluarte, 2012a, p. 193-203. O ser que nega. Disponível em:

<http://www.flusserstudies.net/sites/www.flusserstudies.net/files/media/attachments/g ustavo-o-ser.pdf>. Acesso em: 02 jul. 2012b.

BÍBLIA SAGRADA: antigo e novo testamento. Tradução de João Ferreira de Almeida. Ed. rev. e atualizada no Brasil. Brasília: Sociedade Bíblia do Brasil, 1969.

BLANCHOT, Maurice. O livro por vir. Tradução de Leyla Perrone-Moisés. 2 ed. São Paulo: Martins Fontes, 2013.

BOSI, Ecléa. O tempo vivo da memória. 2 ed. São Paulo: Ateliê Editorial, 2003.

BRANDÃO, Luís Alberto; OLIVEIRA, Silvana M. Pessoa. Sujeito, tempo e espaços ficcionais. Introdução à teoria da literatura. São Paulo: Martins Fontes, 2001.

CHAUÍ, Marilena. Laços de desejo. In: NOVAES, Adauto (Org.). O desejo. São Paulo: Companhia das Letras; Rio de Janeiro: Funarte, 2006.

CHEVALIER, Jean; GHEERBRANT, Alain. Dicionário de símbolos. 14 ed. Tradução de Vera da Costa e Silva. Rio de Janeiro: José Olympio, 1999. 
D’ANGELO, Biagio. Máscaras e (des)mistificações: estratégia para a literatura contemporânea. Revista Via Atlântica - Revista da Área de Estudos Comparados de Literaturas de Língua Portuguesa da USP. São Paulo, n. 13, 2008, p. 245-248.

ISER, Wolfgang. A interação do texto com o leitor. In: JAUSS, Hans Robert et al. $A$ literatura e o leitor: textos de estética da recepção. Tradução de Luiz Costa Lima. Rio de Janeiro: Paz e Terra, 1979, p. 83-132.

SANTIAGO, Silviano. O narrador pós-moderno. In: SANTIAGO, Silviano. Nas malhas da letra: ensaios. Rio de Janeiro: Rocco, 2002.

VILLA-LOBOS, Heitor. Nessa rua tem um bosque. 1925. Disponível em:

<https://www.letras.mus.br/cantigas-populares/983995/>. Acesso em: 01 mar. 2017.

Recebido em 12 de março de 2018.

Aceito em 2 de abril de 2018. 